Intecoms: Journal of Information Technology and Computer Science

Volume 1 Nomor 2, Desember 2018

e-ISSN : 2614-1574

p-ISSN : 2621-3249

DOI : https://doi.org/10.31539/intecoms.v1i2.290

\title{
PERANCANGAN APLIKASI PENGOLAHAN DATA LOGISTIK PADA KANTOR CABANG BRI SOLOK
}

\section{DESIGN OF LOGISTIC DATA PROCESSING APPLICATION IN BRI SOLOK BRANCH OFFICE}

\author{
Cendra Wadisman \\ Universitas Putra Indonesia YPTK Padang \\ cendra_wadisman@upiyptk.ac.id
}

\begin{abstract}
With the development of information technology companies are required to improve the efficiency and quality of service. The logistics department not only serves to support the office operations but one of the functions that will improve the effectiveness and efficiency of the company. This research was conducted to assist the logistics department in making efficient use of time, energy and cost in making logistic report at Bank Rakyat Indonesia branch of Solok. In this research will be made data processing logistics system using Java programming language and MySQL database. Based on data obtained by way of observation and interview further data analyzed to make system design as needed.
\end{abstract}

Keywords : Data Processing Logistics, JAVA, MYSQL

\section{ABSTRAK}

Dengan semakin berkembangnya teknologi informasi perusahaan dituntut untuk meningkatkan efisiensi dan kualitas pelayanan. Bagian logistik tidak hanya berfungsi untuk pendukung operasional perkantoran namun salah satu fungsi yang akan meningkatkan efektivitas dan efisiensi perusahaan tersebut. Penelitian ini dilakukan untuk membantu bagian logistik dalam mengefisienkan penggunaan waktu, tenaga dan biaya dalam pembuatan laporan logistik pada Bank Rakyat Indonesia cabang Solok. Pada penelitian ini akan dibuat sistem pengolahan data logistik menggunakan bahasa pemrograman Java dan database MySQL. Berdasarkan data yang diperoleh dengan cara observasi dan interview selanjutnya data dianalisa untuk membuat rancangan sistem sesuai kebutuhan.

Kata Kunci: Pengolahan Data Logistik, JAVA, MYSQL

\section{PENDAHULUAN}

Manajemen logistik merupakan aktivitas yang sangat penting dalam sebuah perusahaan atau perkantoran. Fungsi logistik tidak lagi dipandang sebagai pendukung dalam operasional perkantoran, namun sebagai salah satu fungsi yang akan meningkatkan efektivitas dan efisiensi instansi tersebut. Adanya dinamika dalam internal instansi ataupun antar instansi menuntut pengelolaan logistik untuk menggunakan pendekatan baru yang mampu meningkatkan efisiensi dan kualitas pelayanan seperti Nozomi dan Hamzah (2018) melakukan penelitian tentang perancangan pengolahan data
Surat Izin Usaha Angkutan Barang pada kantor dinas Perhubungan Kabupaten Lima Puluh Kota berbasis Web. Sama Halnya dengan Nawang dkk (2017) membangun sistem informasi pengolahan data barang berbasis desktop. Untuk meningkatkan kualitas pelayanan tersebut dapat dilakukan penelitian lanjutan dengan memanfaatkan data yang ada untuk mengelompokan logistik yang paling sering digunakan dengan Alogritma KMeans. Penelitian mengenai penerapan Data Mining menggunakan Algoritma K-Means sudah banyak dilakukan oleh orang-orang yang berada dibidang teknologi informasi atau pada bidang 
lainnya, salah satunya pemilihan pelanggan potensial pada MC Laundry (Putra, R., \& Wadisman, C., 2018). Penelitian lanjutan yang dapat dilakukan seperti manajemen inventori logistik, judul penelitian mengenai manajemen inventory sudah pernah dilakukan seperti sistem manajemen inventory komputer menggunakan Near Field Communication berbasis android (Hamzah \& Purwati, 2017).

PT.BRI (Persero) yang didirikan sejak tahun 1895 didasarkan pelayanan pada masyarakat kecil sampai sekarang tetap konsisten, yaitu dengan fokus pembiayaan kepada Usaha Mikro Kecil dan Menengah (UMKM). Hal ini tercermin dari penyaluran KUK (Kredit Usaha Kecil). Pada proses penyimpanan dan peminjaman uang dibutuhkan buku untuk menabung, kertas berisi data diri untuk pengajuan peminjaman, kertas dengan kopsurat, nota peminjaman dan masih banyak lagi barang logistic yang dibutuhkan dalam proses untuk peminjaman dan penyimpanan uang. Proses pengadaan barang logistik dikerjakan oleh bagian logistik. Sampai saat ini bagian logistik hanya menggunakan sistem pengelolaan data logistik secara manual, sehingga dapat memungkinkan terjadinya kesalahan dalam pembuatan laporan logistik. Sistem yang dilakukan secara manual juga tidak mengefisienkan waktu, tenaga dan biaya dalam pembuatan laporan logistik pada Kantor Cabang BRI Solok.

Definisi sistem informasi menurut Tata Sutabri (2012) adalah suatu sistem di dalam suatu organisasi yang mempertemukan kebutuhan pengolahan transaksi harian yang mendukung fungsi operasi organisasi yang bersifat manajerial dengan kegiatan strategi dari suatu organisasi untuk dapat menyediakan laporan-laporan yang diperlukan oleh pihak luar tertentu.

\section{METODE PENELITIAN}

Alat Bantu dalam Merancang Sistem

Agar perancangan sistem dapat berjalan lancar sesuai dengan rencana, selain metodologi juga dibutuhkan alat bantu (tools). Beberapa alat bantu perancangan yang sering digunakan adalah ASI, CD, DFD, ERD, dan FlowChart.

\section{ASI (Aliran Sistem Informasi)}

Aliran sistem informasi merupakan alat bantu yang menunjukkan arus pekerjaan secara keseluruhan dari sistem. ASI dapat digunakan dengan menggunakan simbol-simbol seperti pada tabel 1 :

Tabel. 1 Simbol Pada Aliran Sistem Informasi

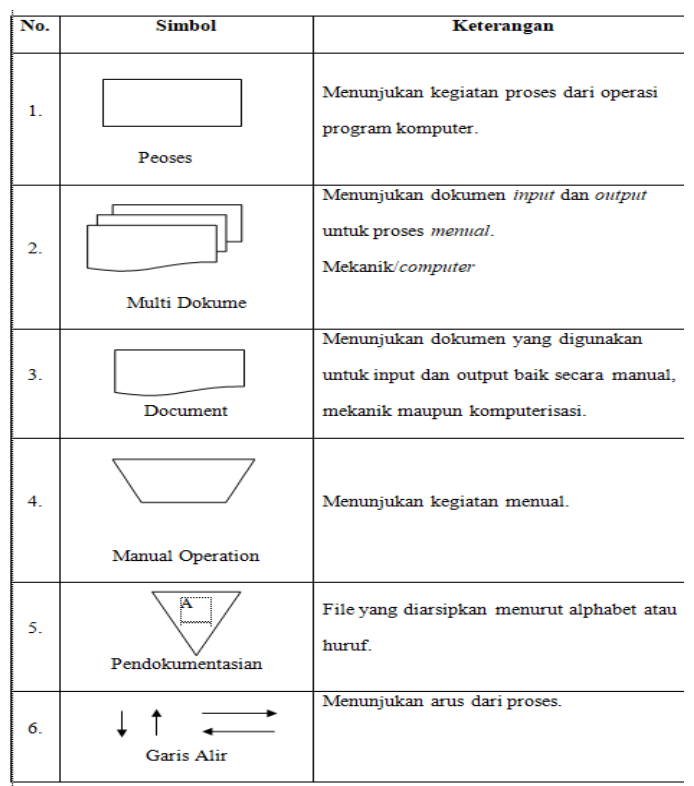

Sumber: (Rosa, A.S., dan M. Shalahuddin, 2011)

\section{DFD (Data Flow Diagram)}

Data Flow Diagram (DFD) adalah sebuah alat yang menggambarkan aliran data sampai sebuah sistem selesai, dan kerja atau proses dilakukan dalam sistem tersebut. Istilah dalam bahasa indonesianya adalah diagram aliran data (Indrajani, S.Kom., MM. 2015). 
Beberapa symbol yang digunakan pada DFD seperti tabel 2.

Tabel. 2 Simbol Context Diagram Dan Data Flow Diagram

\begin{tabular}{|c|c|c|}
\hline $\mathbf{N a}$ & Sinbol & Keterangan \\
\hline 1. & KesatuanLuar & $\begin{array}{l}\text { Mrupakan kesaturan luar (entity) di lingkungan } \\
\text { luar sistemyang dapat berupa orang organisasi, } \\
\text { atau sistemlainnya yang berada di lingkungn } \\
\text { luarnya yang akanmenberikan input atau } \\
\text { menerima autput. }\end{array}$ \\
\hline 2 & Proses & $\begin{array}{l}\text { Merupakan kegiatar/ kejjayang dilakukan oleh } \\
\text { orang mesin atau komputer dari suatu anus data } \\
\text { yangmasuk ke dalamproses untuk dihasilkan } \\
\text { ans data yang akan keluar dari proses }\end{array}$ \\
\hline 3. & Penyimpanan Data & $\begin{array}{l}\text { Merupakan simpanan dari data yang dapat berupa } \\
\text { statu file atau database di sistemkonputer. }\end{array}$ \\
\hline 4. & Anus Data & 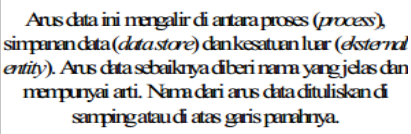 \\
\hline
\end{tabular}

\section{ERD (Entity Relationship Diagram)}

Model Entity-Relationship berisi komponen-komponen dari suatu himpunan entitas dan himpunan relasi yang masing-masing dilengkapi dengan atribut-atribut yang mempresentasikan seluruh fakta yang ditinjau sehingga dapat diketahui hubungan antara entityentity yang ada dengan atributatributnya. Relasi adalah hubungan antara beberapa entitas. Simbol-simbol ERD dapat dilihat pada tabel 3.

Tabel. 3 Simbol Entity Relationship Diagram

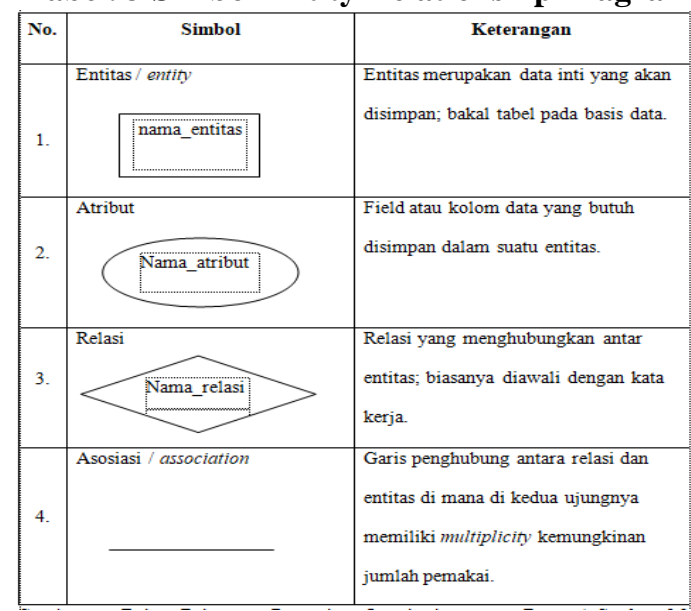

Sumber: (Rosa, A.S., dan M. Shalahuddin, 2011)

\section{Bagan Alir Program (Flowchart)}

Program flow-chart digunakan untuk menggambarkan algoritma atau proses. Aliran data tidak digambarkan dalam program flow-chart melainkan fokus pada urutan proses dalam sebuah aplikasi. Program flow-chart digambar dengan menggunakan simbol-simbol seperti pada tabel 4.

Tabel. 4 Simbol Bagan Alir Program

\begin{tabular}{|c|c|c|}
\hline No. & Simbol & Keterangan \\
\hline 1. & Proses & $\begin{array}{l}\text { Proses, digunakan untuk pengolahan } \\
\text { aritmatika dan pemindahan data }\end{array}$ \\
\hline 2. & Terminal & $\begin{array}{l}\text { Terminal, digunakan untuk menunjukan } \\
\text { awal dan akhir program }\end{array}$ \\
\hline 3. & Preparation & $\begin{array}{l}\text { Preparation, digunakan untuk } \\
\text { memberikan nilai awal pada suatu } \\
\text { variabel. }\end{array}$ \\
\hline 4. & Keputusan & $\begin{array}{l}\text { Keputusan, digunakan untuk mewakili } \\
\text { operasi perbandingan logika. }\end{array}$ \\
\hline 5. & Proses terdefinisi & $\begin{array}{l}\text { Proses terdefinisi, Digunakan untuk } \\
\text { proses yang detailnya dijelaskan } \\
\text { terpisah. }\end{array}$ \\
\hline 6. & Penghubung & $\begin{array}{l}\text { Penghubung, digunakan untuk } \\
\text { menujukan hubungan anus proses yang } \\
\text { terputus masih dalam halaman yang } \\
\text { sama. }\end{array}$ \\
\hline 7. & Penghubung Halaman Lain & $\begin{array}{l}\text { Penghubung Halaman Lain , digunakan } \\
\text { untukmenunjukan hubungan arus } \\
\text { proses yang terputus masith dalam } \\
\text { halaman yang sama. }\end{array}$ \\
\hline
\end{tabular}


MYSQL

MySQL adalah salah satu jenis database server yang sangat terkenal. Kepopulerannya disebabkan mysql menggunakan sql sebagai bahasa dasar untuk mengakses databasenya. Selain itu, ia bersifat open source (anda tidak perlu membayar untuk menggunakannya) pada berbagai platform (kecuali untuk jenis enterprise, yang bersifat komersial). MySQL tergolong sebagai DBMS (Database Management System).Itulah sebabya, istilah seperti table, baris, dan kolom digunakan pada mysql.Pada mysql, sebuah database mengandung satu kata atau sebuah table.Table terdidri atas sejumlah baris dan setiap baris mengandung satu atau sejumlah kolom (Abdul Kadir, 2013).

\section{Konsep Dasar Pemograman Java}

Java adalah merupakan salah satu bahasa pemograman yang sangat pupolar dalam dunia programmer. Banyak IDE yang mendukung bahasa pemograman Java seperti : NetBeans, Eclipse, dan lainnya. NetBeans merupakan salah satu IDE yang paling tangguh saat ini dalam melakukan pemrograman Java. Selain itu, NetBeans menyediakan paket yang lengkap dalam pemrograman dari pemrograman standar (aplikasi desktop), pemrograman enterprise, dan pemrograman perangkat mobile.

SDLC atau System Development Life Cycle adalah salah satu metodologi yang digunakan dalam perancangan sistem informasi. Metodologi adalah seperangkat prosedur atau aturan-aturan yang digunakan untuk memecahkan masalah yang rumit berdasarkan langkah-langkah yang jelas. System Development Life Cycle seperti pada gambar di bawah ini :

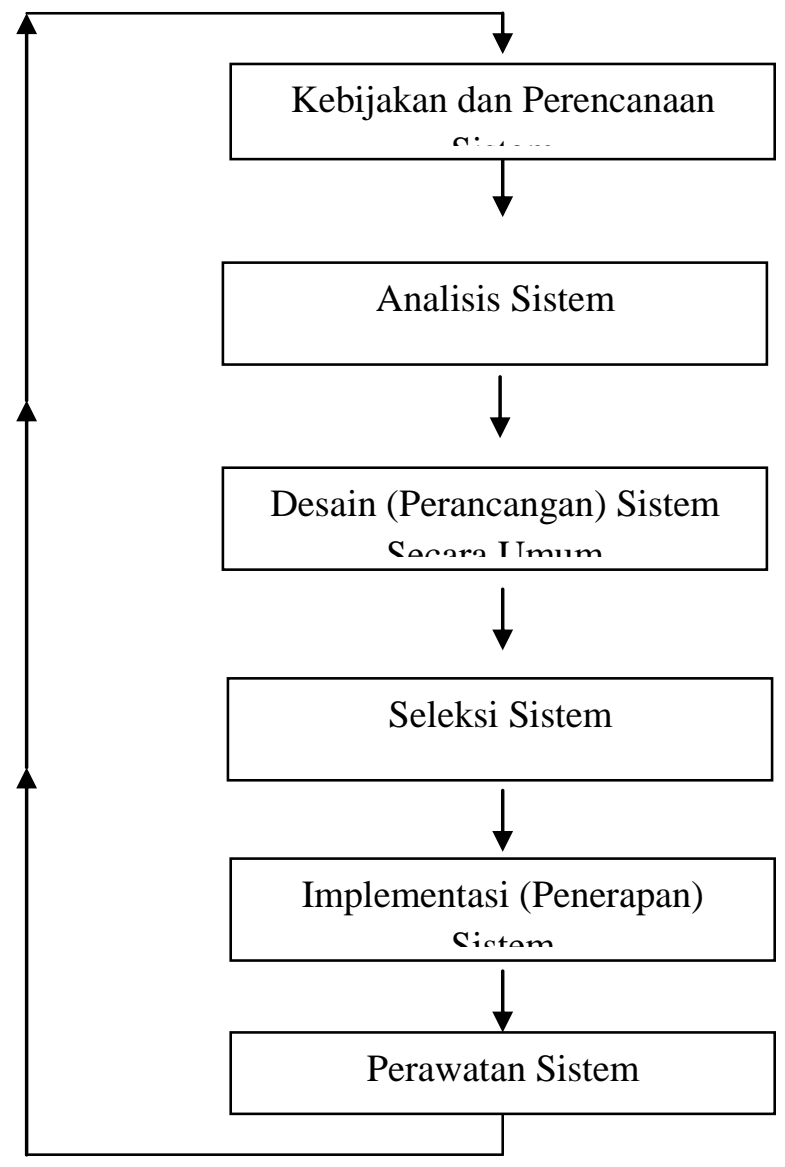

Gambar. 1 Siklus Hidup Pengembangan Sistem

\section{HASIL DAN PEMBAHASAN}

\section{Analisa Sistem}

Analisa sistem sangat penting dilakukan, karena disini penulis dituntut untuk mengetahui kelemahan-kelemahan sistem, hambatan, kendala dan kesempatan yang tidak mampu diraih oleh sistem dalam informasi pengolahan data logistik yang ada sekarang guna dicarikan alternatif pemecahan masalahnya.

Berdasarkan survei yang telah dilakukan penulis secara keseluruhan, Kantor Cabang BRI Solok dalam melakukan proses pengolahan data logistik saat ini memiliki kelemahan yang ditemukan dalam proses pengolahan data logistik. 


\section{Aliran Sistem Informasi yang Sedang Berjalan}

Aliran sistem informasi yang sedang berjalan seperti gambar 2 .

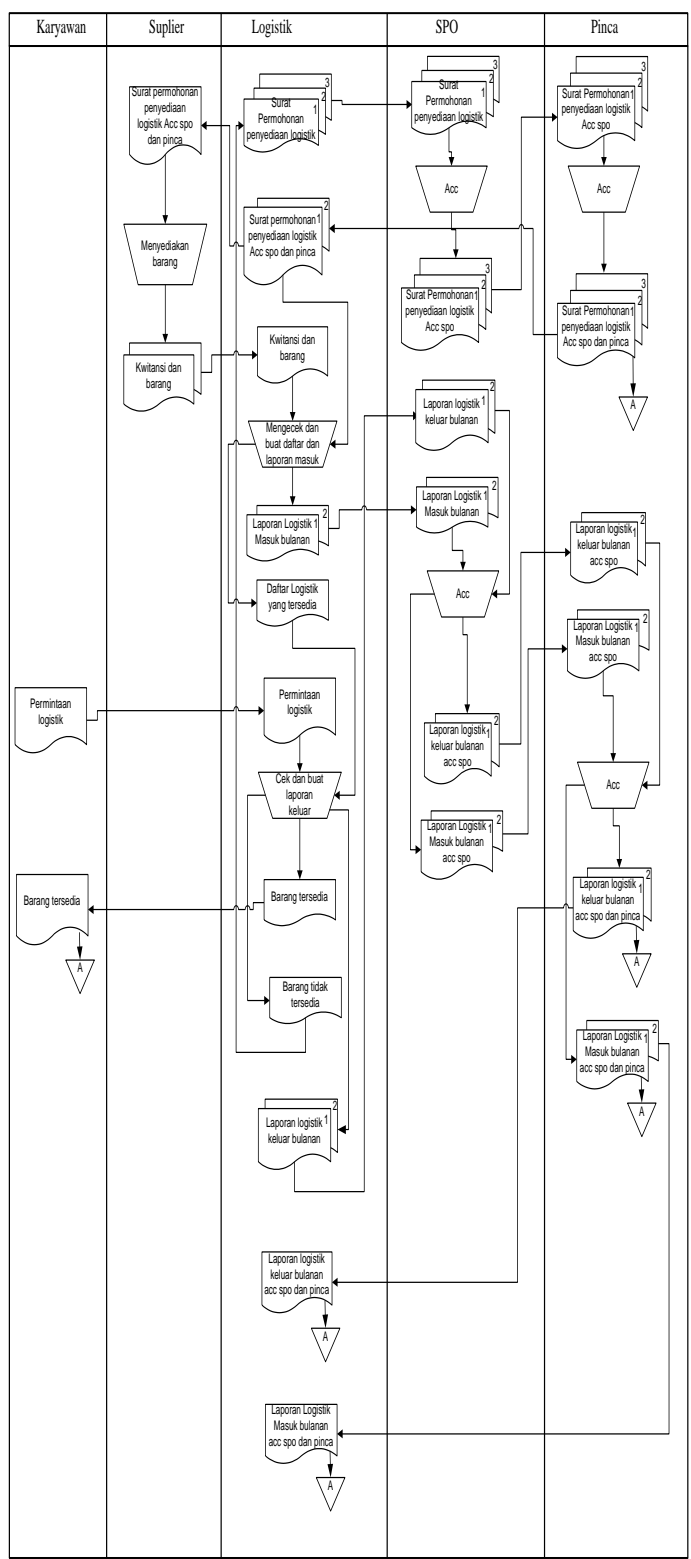

Gambar 2. Aliran Sistem Informasi Lama

\section{Desain Sistem}

Desain sistem merupakan tahap setelah analisa sistem. Tujuan dari disain sistem ini yaitu untuk mempercepat pembuatan laporan. Desain sistem pada hakekatnya bukanlah sekedar mempercepat atau mengoptimalisasikan kegiatan operasi tapi juga mencakup standarisasi dengan hasil dalam penghematan waktu dan biaya.

\section{Aliran Sistem Baru}

Dilihat dari aliran sistem yang berjalan pada saat ini ternyata sistem tersebut belum berjalan secara optimal dan efisien. Oleh karena itu perlu dilakukan perubahan sistem yang lama ke sistem yang baru agar dapat meningkatkan kinerja dan menunjang aktifitas kerja, seperti pada gambar 3 .

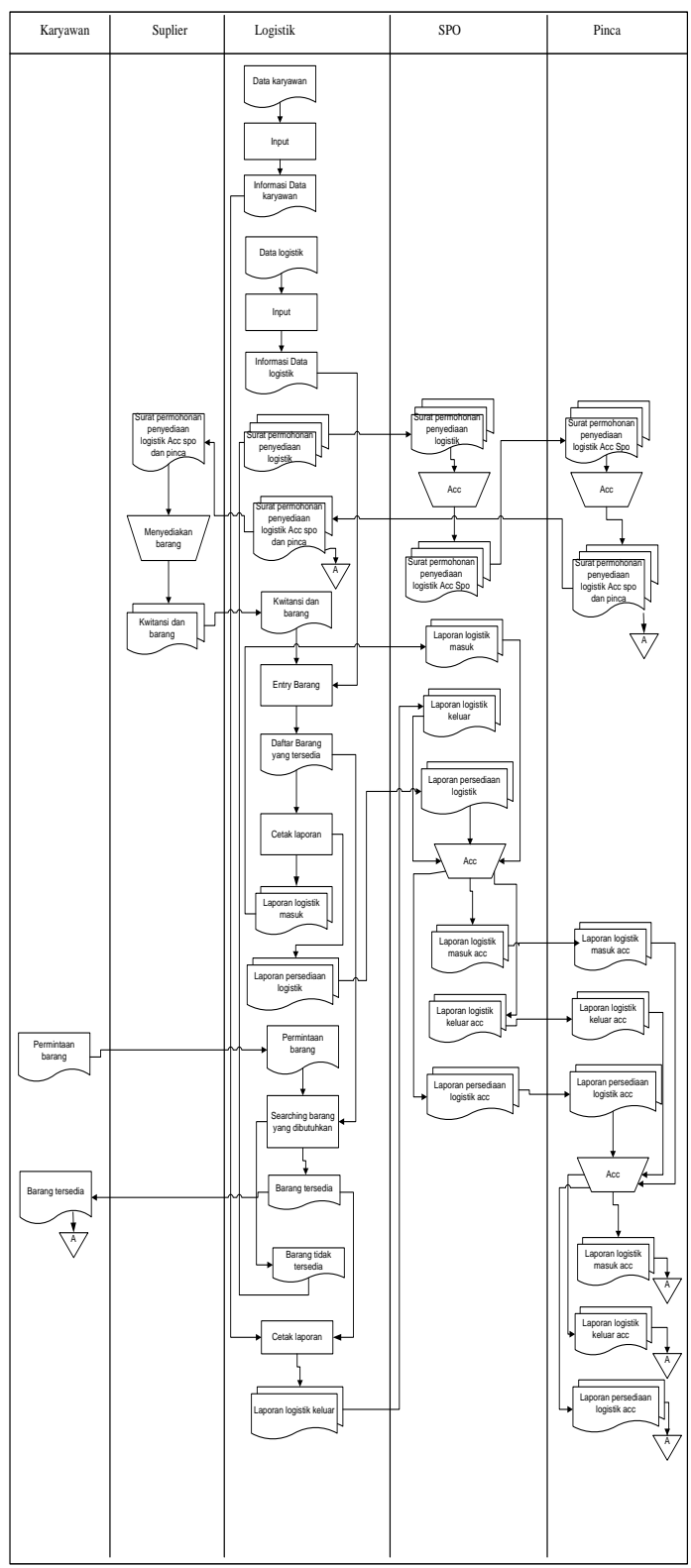

Gambar 3. Aliran Sistem Informasi Baru 


\section{Context Diagram}

Context Diagram merupakan alat bantu perancangan secara global yang memperlihatkan sistem secara umum dan bagian-bagian dari sub sistem yang terlibat dalam sistem secara keseluruhan, keterkaitan dan interaksi antar sub-sub sistem, seperti pada gambar 4.

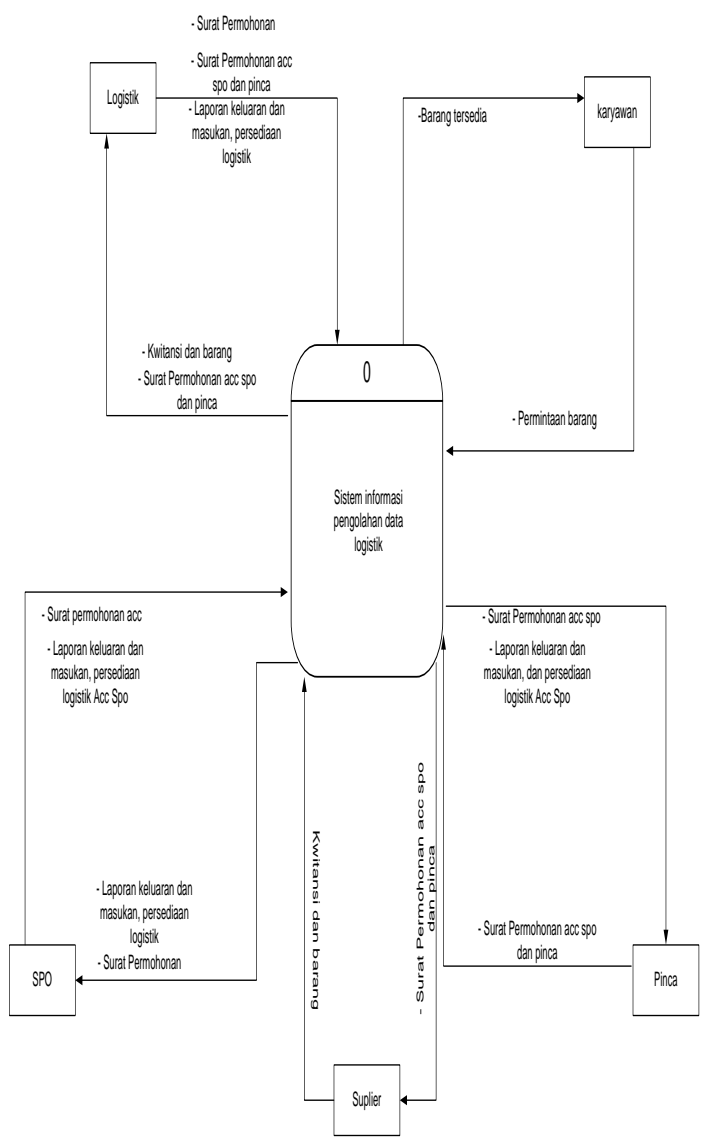

Gambar. 4 Context Diagram Sistem Pengolahan Data Logistik

\section{Data Flow Diagram Level 0}

Data Flow Diagram level 0 menggambarkan sebuah Sistem Informasi yang menitikberatkan pada proses (fokus pada Proses). Dengan mengacu kepada Context Diagram, proses yang terjadi diuraikan kedalam bentuk Data Flow Diagram (DFD) level 0 , seperti pada gambar 5 .

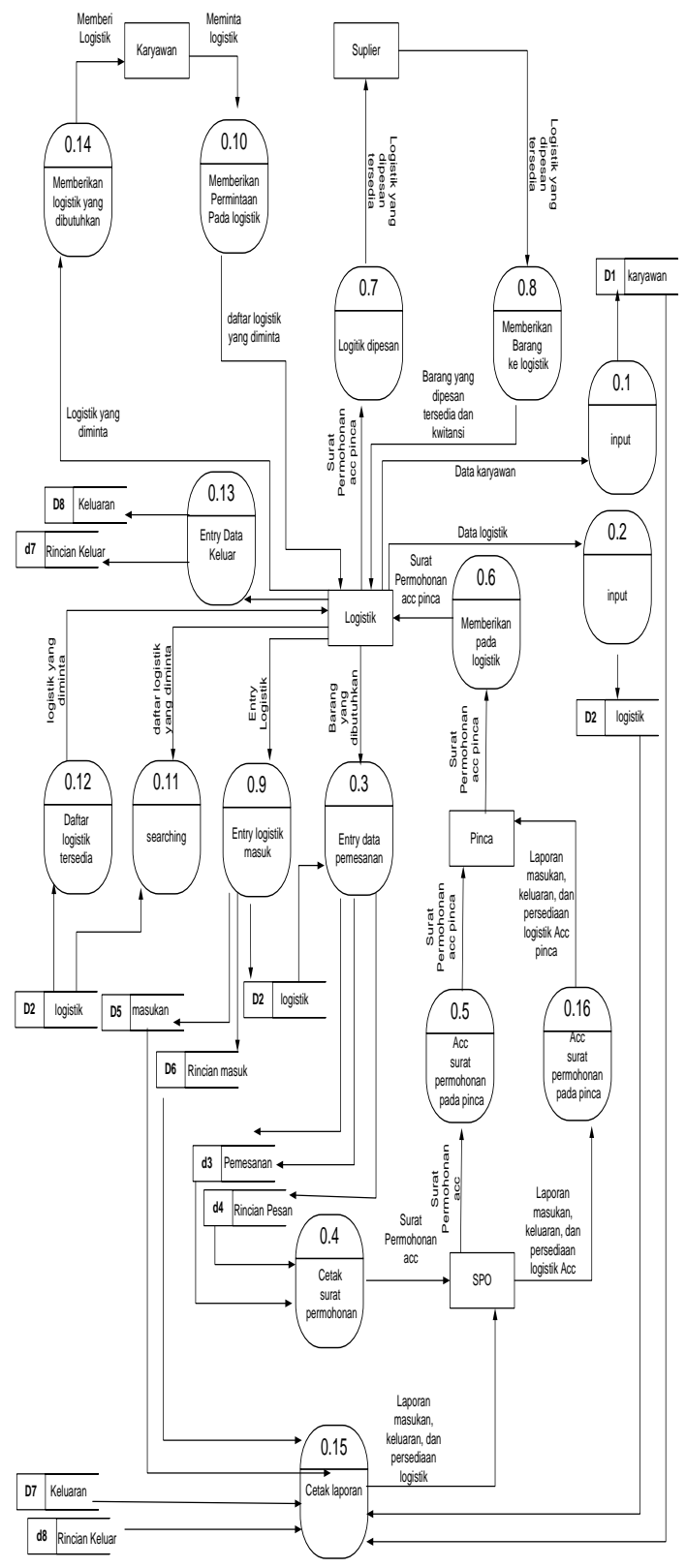

Gambar. 5 Data Flow Diagram Level 0

\section{Entity Relatioship Diagram}

Entity Relationship Diagram (ERD) merupakan suatu dokumentasi data yang mengidentifikasikan entity data dan memperlihatkan hubungan yang ada diantara entity tersebut dengan menggunakan atribut key field (Primary Key Atribut) dari masing-masing entity seperti gambar 6 . 


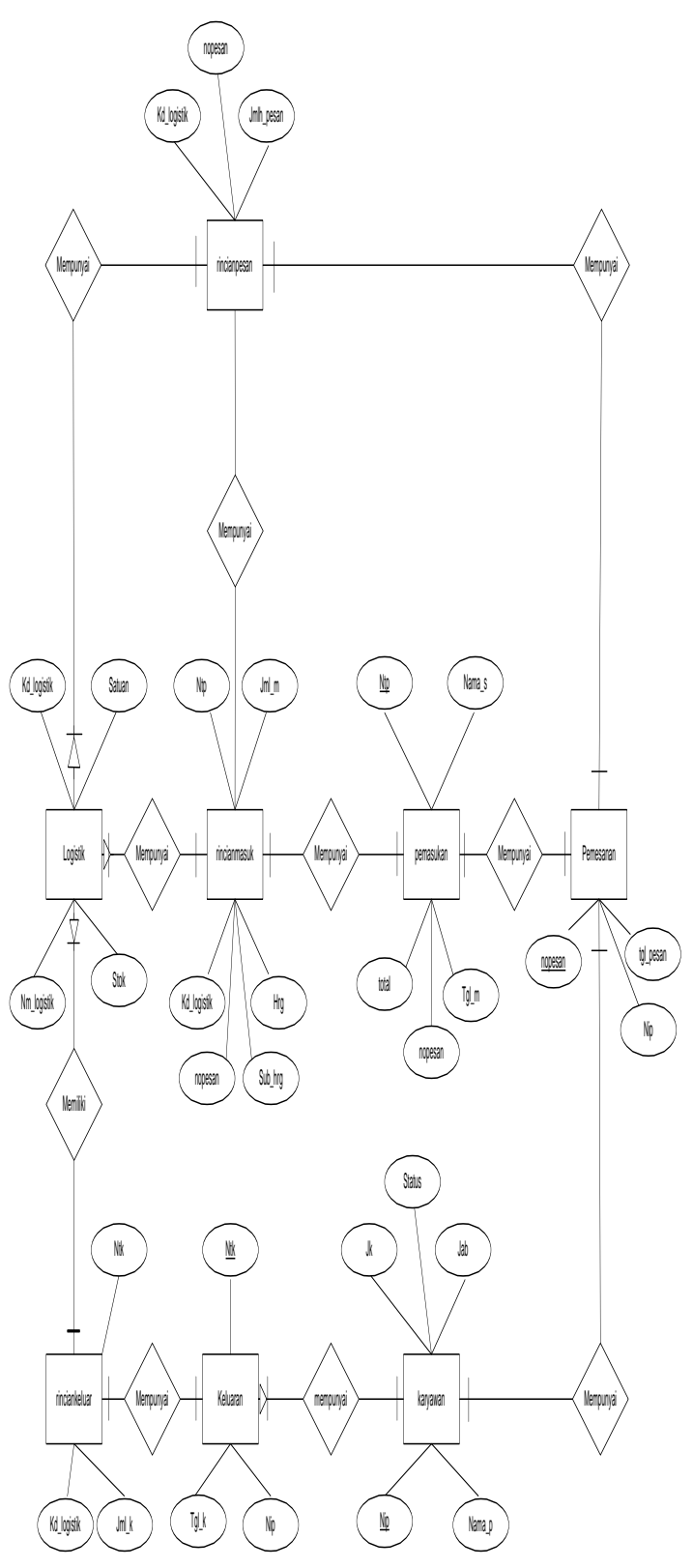

Gambar 6. Entity Relationship Diagram

\section{Struktur Program}

Stuktur Program adalah gambaran dari sebuah rangkaian modul-modul program yang saling terkait satu sama lain yang terlihat dalam proses pengolahan data. Pembuatan struktur program ini dimaksudkan untuk mempermudah dalam memahami keterkaitan modul-modul program dan untuk memperlihatkan jenjang atau hirarki dari program yang dirancang. Dengan demikian dapat dijabarkan urutan kerja dari tiap modul program. Adapun bentuk struktur program seperti gambar 7.

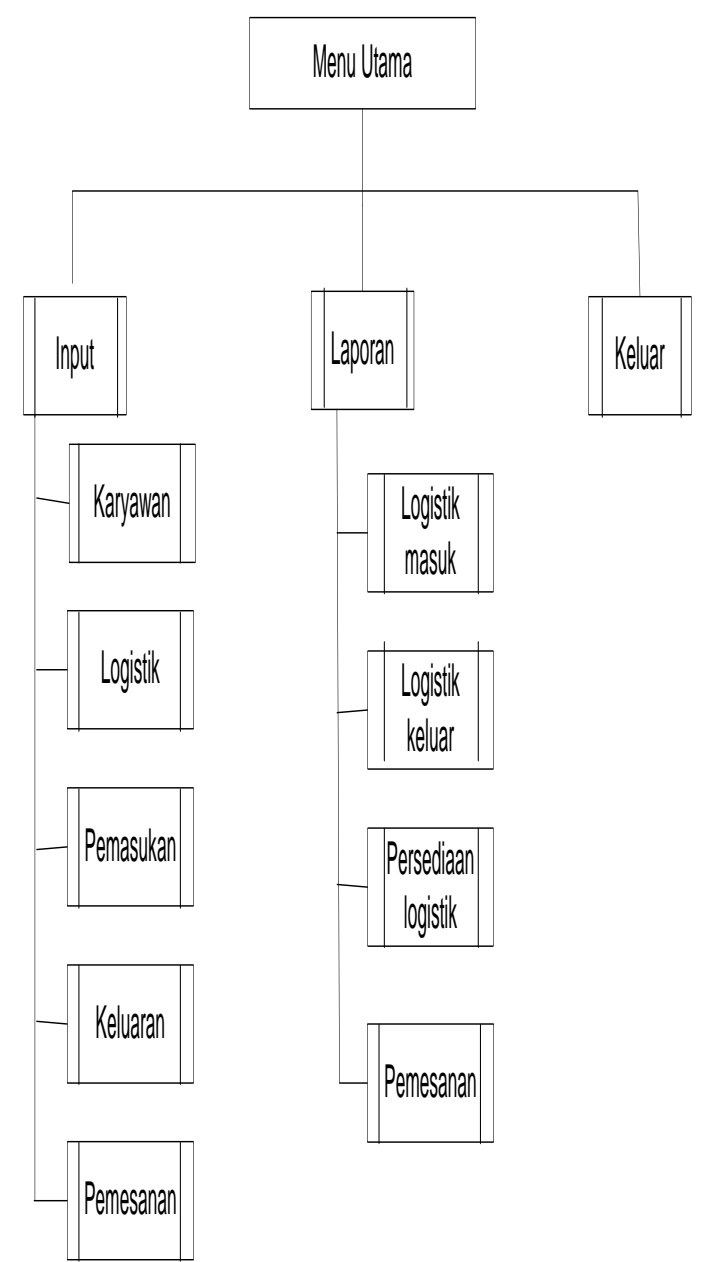

Gambar 7. Struktur Program

\section{Pengujian Sistem}

Pengujian system dilakukan dengan mengeksekusi program aplikasi yang telah dibuat dan menampilkannya berdasarkan menu-menu yang ada pada program aplikasi system pengolahan data logistik kantor cabang BRI Solok.

\section{Halaman Login}

Halaman login berfungsi untuk bagian logistik masuk ke dalam sistem, untuk dapat login maka bagian logistik dapat menjalankan aplikasi kemudian masukkan username dan password yang tertera pada form login tersebut seperti pada gambar 8 . 


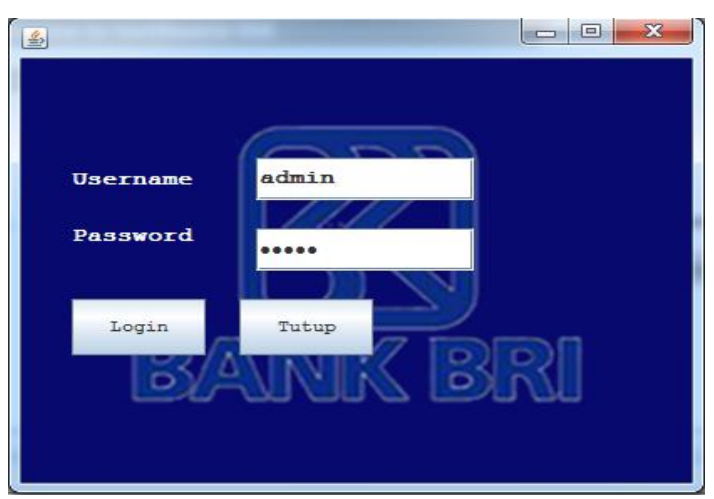

Gambar. 8 Halaman Login

\section{Homepage Aplikasi}

Homepage Aplikasi terdiri dari beberapa menu. Menu-menu pada form Homepage ini berfungsi agar bagian logistik dapat melihat serta melakukan penginputan logistik yang masuk dan keluar. Menu-menu yang terdapat pada form Homepage antara lain, Input, Laporan, Keluar. Tampilan halaman utama pada formHomepage dapat dilihat pada gambar 9 .

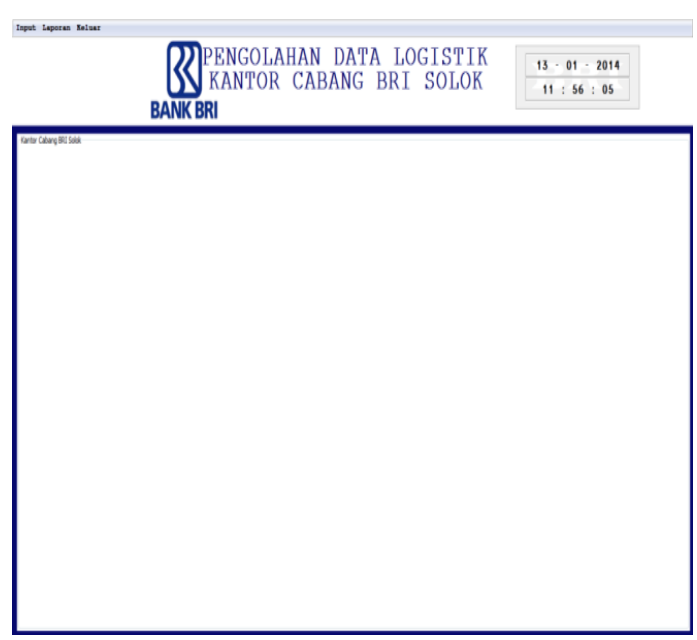

Gambar. 9 Homepage Aplikasi

\section{Tampilan Input Data Karyawan}

Tampilan Input Data Karyawan berfungsi apabila bagian logistikingin melakukan penginputan data karyawan, untuk melakukan penginputan, bagian logistik dapat mengklik menu Input yang teletak di bagian atas dan klik karyawan atau tekan $\mathrm{Ctrl}+\mathrm{K}$ dan akan muncul Tampilan Input Data Karyawan seperti gambar 10.

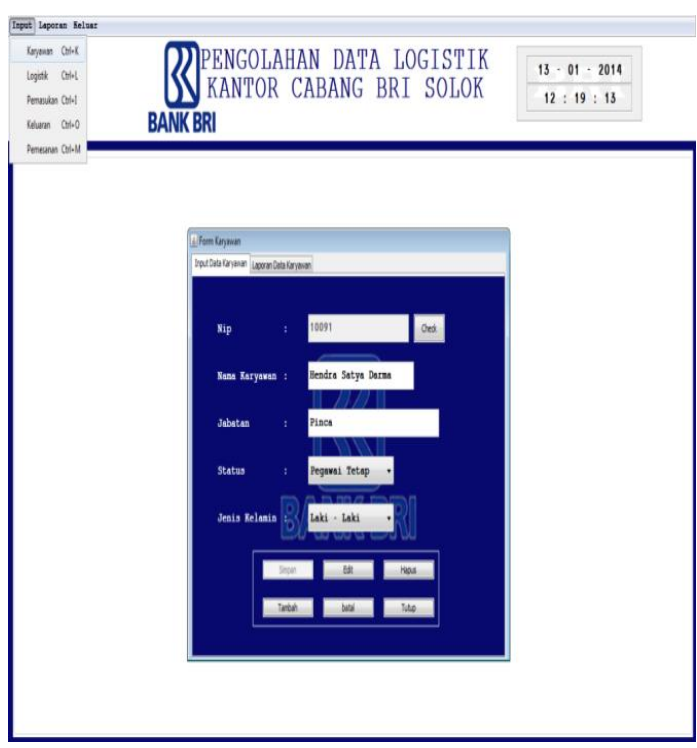

Gambar. 10 Tampilan Input Data Karyawan

\section{Tampilan Input Data Logistik}

Tampilan Input Data Logistik berfungsi apabila bagian logistikingin melakukan penginputan data logistik, untuk melakukan penginputan, bagian logistik dapat mengklik menu Input yang teletak di bagian atas dan klik logistik atau tekan Ctrl $+\mathrm{L}$ dan akan muncul Tampilan Input Data Logistik seperti gambar 11.

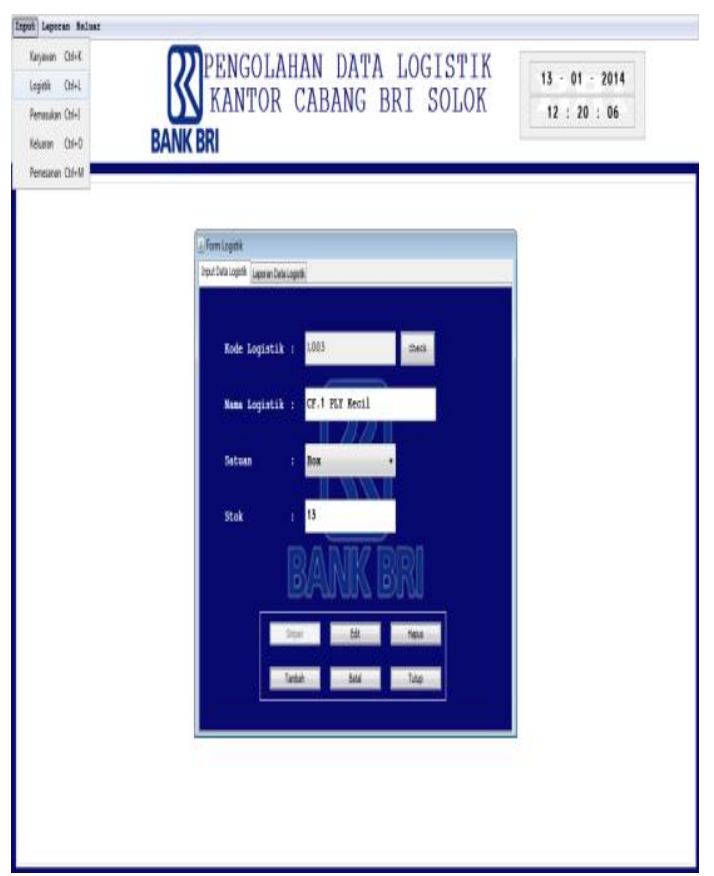

Gambar. 11 Tampilan Input Data Logistik 


\section{Tampilan Input Data Masukan Logistik}

Tampilan Input Data Masukan Logistik berfungsi apabila bagian logistikingin melakukan penginputan data logistik masuk, untuk melakukan penginputan, bagian logistik dapat mengklik menu Input yang teletak di bagian atas dan klik pemasukan atau tekan Ctrl + I dan akan muncul Tampilan Input Data Masukan Logistik seperti gambar 12 .

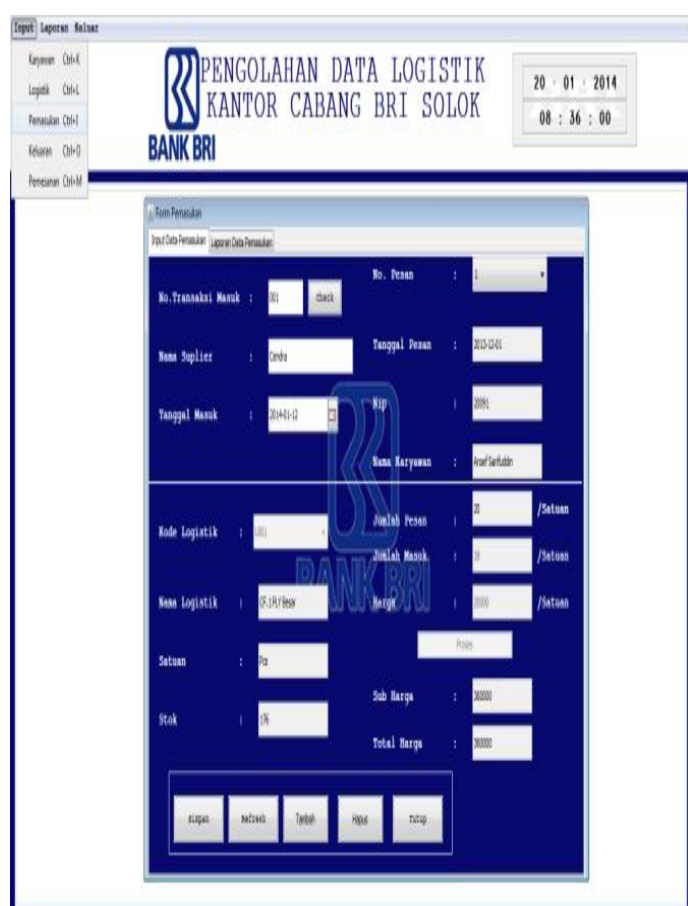

Gambar. 12 Tampilan Input Data Masukan Logistik

\section{Tampilan Input Data Keluaran Logistik}

Tampilan Input Data Keluaran Logistik berfungsi apabila bagian logistik ingin melakukan penginputan data logistik keluar, untuk melakukan penginputan, bagian logistik dapat mengklik menu Input yang teletak di bagian atas dan klik keluaran atau tekan Ctrl + O dan akan muncul Tampilan Input Data Keluaran Logistik seperti gambar 13.

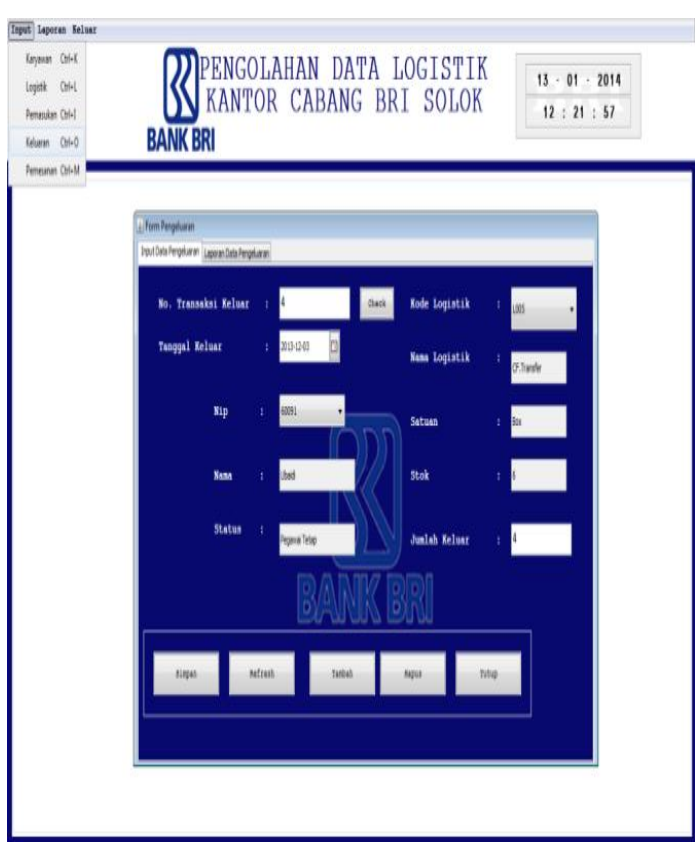

Gambar. 13 Tampilan Input Data Keluaran Logistik

\section{Tampilan Input Data Pemesanan}

Tampilan Input Data Pemesanan berfungsi apabila bagian logistikingin melakukan penginputan data pemesanan logistik, untuk melakukan penginputan, bagian logistik dapat mengklik menu Input yang teletak di bagian atas dan klik pemesanan atau tekan $\mathrm{Ctrl}+\mathrm{M}$ dan akan muncul Tampilan Input Data Pemesanan seperti gambar 14.

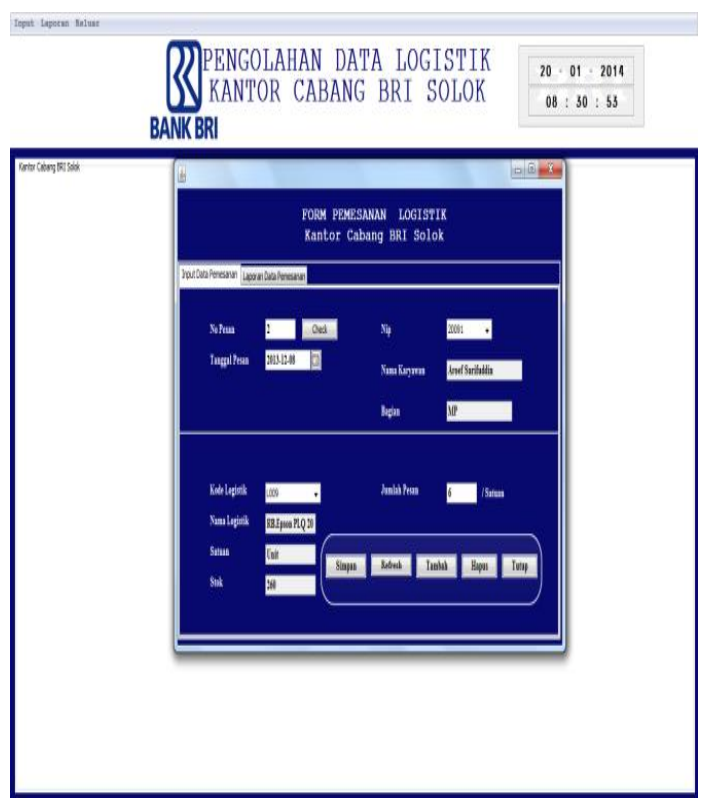

Gambar. 14 Input Data Pemesanan 


\section{Halaman Laporan Pengeluaran Logistik}

Halaman Laporan Pengeluaran Logistik ini berfungsi agar bagian logistik dapat melihat data logistik yang keluar dan disini bagian logistik juga dapat mencetak laporan pengeluaran logistik. Untuk masuk ke halaman laporan, klik laporan yang tertera pada menu utama dan klik menu laporan kemudian klik logistik keluar dan klik cetak seperti pada gambar 15 .

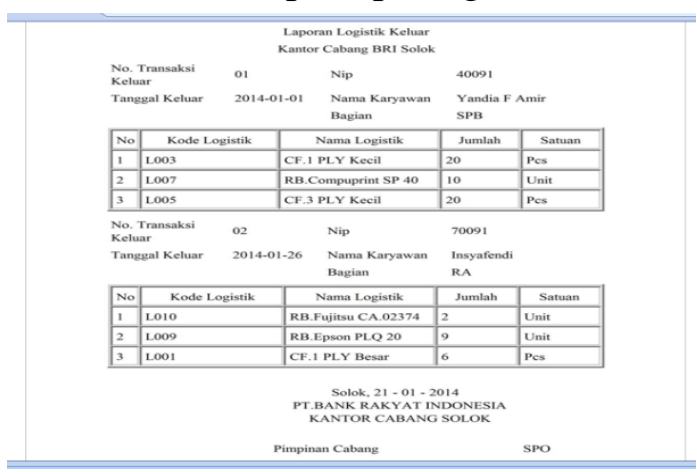

Gambar. 15 Halaman Laporan Pengeluaran Logistk

\section{Halaman Laporan Pemasukan Logistik}

Halaman Laporan Pemasukan Logistik ini berfungsi agar bagian logistik dapat melihat data logistik yang masuk dan disini bagian logistik juga dapat mencetak laporan pemasukan logistik. Untuk masuk ke halaman laporan, klik laporan yang tertera pada menu utama dan klik menu laporan kemudian klik logistik masuk dan klik cetak seperti pada gambar 15 .

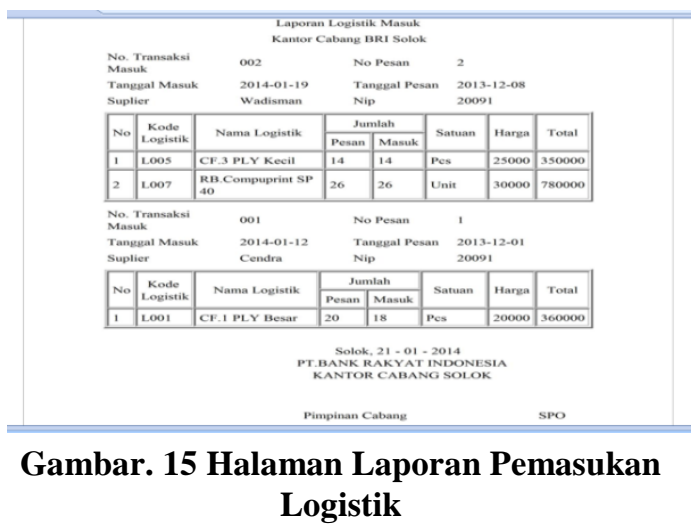

\section{Halaman Surat Permohonan}

Halaman Surat Permohonan ini berfungsi agar bagian logistik dapat melihat data logistik yang yang ingin dipesan dan disini bagian logistik juga dapat mencetak laporan surat permohonan logistik. Untuk masuk ke halaman laporan, klik laporan yang tertera pada menu utama dan klik menu laporan kemudian klik pemesanan dan klik cetak seperti pada gambar 16 .

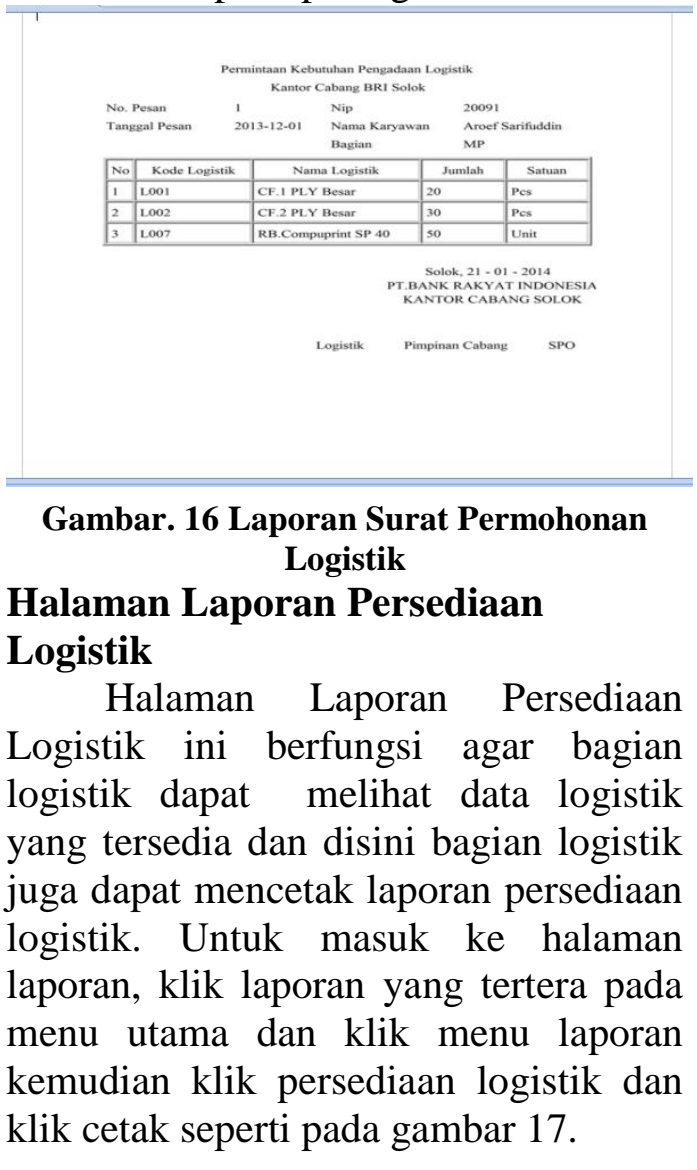

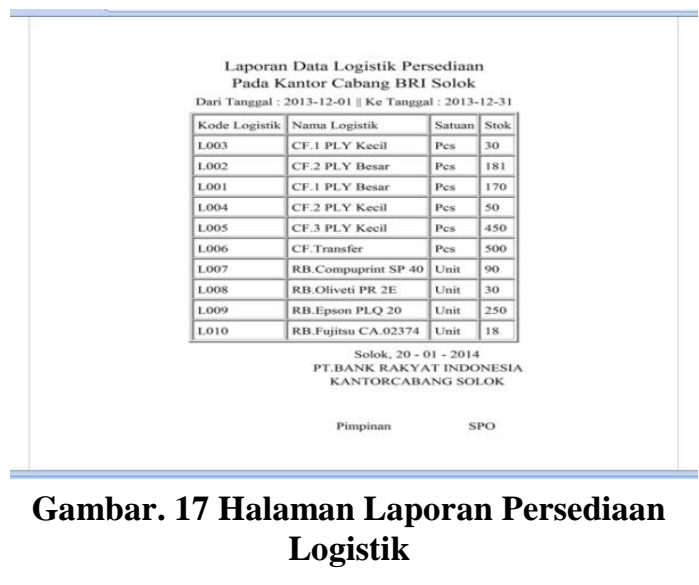




\section{SIMPULAN}

Dari uraian yang telah dikemukakan pada bab-bab sebelumnya berdasarkan hasil penelitian yang telah dilakukan pada Kantor Cabang BRI Solok, maka dapat diambil beberapa kesimpulan antara lain :

1. Pengolahan data logistik yang menggunakan sistem manual memerlukan waktu yang lama dan data yang dihasilkan kurang akurat.

2. Dengan adanya pengaplikasian bahasa pemrograman Java dan Database Mysql pada pengolahan data logistik, data akan tersusun dalam file dan disimpan dalam media elektronik yang akan menghemat ruang pengarsipan dan mudah dalam pencarian data.

3. Dengan adanya pengaplikasian bahasa pemrograman Java dan Database Mysql pada pengolahan data logistik maka keamanan data dapat terjamin, dan dapat mengatasi kemungkinan kerusakan dan kehilangan data.

4. Sistem yang lama tidak seluruhnya dibuang atau digantikan dengan sistem yang baru karena dalam menjalankan sistem yang baru ini masih memerlukan sistem yang lama.

\section{DAFTARPUSTAKA}

Hamzah, M., \& Purwati, A. (2017). Sistem Manajemen Inventori Komputer Menggunakan Near Field Communication Berbasis Android Studi Kasus di STIE Pelita Indonesia Pekanbaru. Journal of Economic, Bussines and Accounting (COSTING), 1(1), 95104.

https://doi.org/https://doi.org/10.3 $1539 /$ costing.v1i1.46

Indrajani, I. (2015). Data Base Design. Jakarta
Kadir, A. (2013). Pemrograman Data Base Mysql untuk Permula. Yogyakarta: Andi Offset

Nawang, M., Kurniawati, L., \& Duta, D. (2017). Rancang Bangun Sistem Informasi Pengolahan Data Persediaan Barang Berbasis Dekstop Dengan Model Waterfall. Jurnal PILAR Nusa Mandiri, 13(2), 233-238

Nozomi, I., \& Hamzah, M. (2018). Aplikasi Pengolahan Data Surat Izin Usaha Angkutan Barang pada Kantor Dinas Perhubungan Kabupaten Lima puluh Kota. INTECOMS: Journal of Information Technology and Computer Science, 1(1), 110-118. https://doi.org/https://doi.org/10.3 1539/intecoms.v1i1.167

Putra, R., \& Wadisman, C. (2018). Implementasi Data Mining Pemilihan Pelanggan Potensial Menggunakan Algoritma K Means. INTECOMS: Journal of Information Technology and Computer Science, 1(1), 72-77. https://doi.org/https://doi.org/10.3 1539/intecoms.v1i1.141

Rosa, A. S., \& Shalahuddin, M. (2011). Modula Pembelajaran Rekayasa Perangkat Lunak, Modula, Yogyakarta

Sutabri, T. (2012). Analisis Sistem Informasi. Yogyakarta: Andi Offset 